\title{
An evaluation of the management of asymptomatic catheter-associated bacteriuria and candiduria at The Ottawa Hospital
}

\author{
Dawn M Dalen BSP ACPR ${ }^{1}$, Rosemary K Zvonar BScPhm ACPR ${ }^{1}$, Peter G Jessamine Hons BSc MD FRCPC ${ }^{2}$
}

\begin{abstract}
DM Dalen, RK Zvonar, PG Jessamine. An evaluation of the management of asymptomatic catheter-associated bacteriuria and candiduria at The Ottawa Hospital. Can J Infect Dis Med Microbiol 2005;16(3):166-170.
\end{abstract}

BACKGROUND: Asymptomatic catheter-associated urinary tract infections (CAUTIs) are common in hospitalized patients. They are associated with a low incidence of sequelae and morbidity, and in most patients resolve spontaneously on removal of the catheter. As a result, it is not recommended that asymptomatic catheter-associated bacteriuria or candiduria be treated with antimicrobial agents while the catheter remains in place because it may lead to the evolution of resistant flora.

OBJECTIVE: To assess the current management of patients with CAUTIs with respect to antimicrobial therapy at The Ottawa Hospital and the University of Ottawa Heart Institute, Ottawa, Ontario.

METHODS: A prospective observational study over a period of 26 consecutive days was conducted at The Ottawa Hospital (General and Civic campuses) and the University of Ottawa Heart Institute. Inpatients with an indwelling catheter, a positive urine culture and the absence of UTI signs or symptoms were assessed. Patients were followed for five days to determine whether antimicrobials were prescribed.

RESULTS: From March 3 to March 28, 2003, 29 of 119 patients screened met inclusion criteria. Of these 29 patients, 15 (52\%) were prescribed antimicrobials and were therefore considered to be inappropriately managed. Differences were observed between the appropriate and inappropriate management groups in terms of duration of stay to positive urine culture and whether yeast or bacteria were isolated from the culture.

CONCLUSION: Antimicrobial agents were prescribed in over one-half of CAUTI cases, contrary to recommendations from the literature. Education is required to bring this strongly supported recommendation into clinical practice.

Key Words: Asymptomatic; Bacteriuria; Candiduria; Urinary catheter; Urinary tract infection

ndwelling urethral catheters are used in up to $25 \%$ of all hospitalized patients in North America $(1,2)$. Bacteriuria due to catheterization is acquired at a rate of $3 \%$ to $10 \%$ per day, the majority of which are asymptomatic $(1,3)$. The duration of catheterization and antibiotic use also plays a role in the increasing incidence of candiduria (4). Asymptomatic catheter-associated bacteriuria and candiduria are defined as a urine culture of at least $10^{8}$ colony forming units (CFU)/L
Une évaluation de la prise en charge de la bactériurie et de la candidurie asymptomatique associée à une sonde à l'Hôpital d'Ottawa HISTORIQUE : Les infections urinaires asymptomatiques associées à
une sonde (IUAAS) sont courantes chez les patients hospitalisés. Elles
s'associent à une faible incidence de séquelles et de morbidité, et chez la
plupart des patients, elles se règlent spontanément au retrait de la sonde.
Par conséquent, il n'est pas recommandé de traiter une bactériurie ou une
candidurie associée à une sonde à l'aide d'antimicrobiens pendant que la
sonde est en place, en raison du risque d'évolution d'une flore résistante.
OBJECTIF : Évaluer la prise en charge courante des patients atteints
d'une IUAAS pour ce qui est de la thérapie antimicrobienne à l'Hôpital
d'Ottawa et à l'Institut de cardiologie de l'Université d'Ottawa, à Ottawa,
en Ontario.

MÉTHODOLOGIE : Une étude prospective par observation a été menée à l'Hôpital d'Ottawa (campus général et campus Civic) et à l'Institut de cardiologie de l'Université d'Ottawa pendant une période de 26 jours consécutifs. Les patients hospitalisés dotés d'une sonde à demeure, ayant obtenu une culture urinaire positive et ne présentant pas de signes ou symptômes d'infection urinaire ont été évalués. Les patients ont été suivis pendant cinq jours pour déterminer si des antimicrobiens étaient prescrits.

RÉSULTATS : Du 3 mars au 28 mars 2003, 29 des 119 patients dépistés ont respecté les critères d'inclusion. On a prescrit des antimicrobiens à 15 (52\%) de ces 29 patients, ainsi considérés comme mal pris en charge. Des différences ont été observées au sein des groupes bien pris en charge et mal pris en charge pour ce qui est de la durée de l'hospitalisation, de la culture d'urine positive et de l'isolation de champignons ou de bactéries dans la culture.

CONCLUSION : Des antimicrobiens ont été prescrits dans plus de la moitié des cas d'IUAAS, contrairement aux recommandations de la documentation scientifique. De la formation s'impose pour que cette recommandation solidement étayée soit respectée en pratique clinique.

${ }^{1}$ Department of Pharmacy; ${ }^{2}$ Department of Laboratory Medicine, Division of Microbiology, The Ottawa Hospital, Ottawa, Ontario Correspondence: Rosemary K Zvonar, The Ottawa Hospital, Department of Pharmacy, 1053 Carling Avenue, Ottawa, Ontario K1Y 4E9.

Telephone 613-798-5555 ext 15063, fax 613-761-4350, e-mail rzvonar@ottawahospital.on.ca

Received for publication May 12, 2004. Accepted November 22, 2004 
As a result, the literature does not recommend treating patients with antimicrobials while the catheter remains in place $(1,3-9)$. Such unnecessary antimicrobial use may result in an increase in antimicrobial resistance and subject patients to otherwise avoidable adverse effects.

A literature search did not reveal any studies examining adherence to this recommendation. In addition, the current practice regarding the management of asymptomatic CAUTIs at The Ottawa Hospital (Ottawa, Ontario) was not known. We therefore sought to determine the degree to which antimicrobials were being prescribed for asymptomatic CAUTIs at The Ottawa Hospital and the University of Ottawa Heart Institute (Ottawa, Ontario). The Ottawa Hospital is a 1000 bed teaching hospital consisting of two geographically independent inpatient campuses (General and Civic). The University of Ottawa Heart Institute is a 138-bed hospital physically attached to the Civic campus.

\section{METHODS}

A prospective observational chart review was conducted over a period of 26 consecutive days at The Ottawa Hospital (General and Civic campuses) and the University of Ottawa Heart Institute. Eligible patients were identified through a daily microbiology review report printed from the microbiology laboratory at The Ottawa Hospital. An investigator reviewed the daily report for positive cultures specified as "urine, indwelling catheter". The patients' charts were then reviewed by an investigator (DD) for inclusion/exclusion criteria. Those patients that fulfilled the study criteria for asymptomatic CAUTI were followed by the investigator for a duration of five days to determine whether antimicrobial therapy was initiated. In accordance with literature recommendations (1,3-9), optimal patient management was defined as no therapy with antimicrobial agents. Inappropriate patient management was defined as therapy with an antimicrobial agent directed against the organism(s) in the urine culture. Patients with more than one organism isolated were included in the inappropriately managed study group if an antimicrobial was started for any organism.

Data collected included patient demographics, the organism(s) isolated, the duration of hospital stay to positive culture, the duration of catheterization to positive culture, catheter changes or removals, antimicrobial therapy started, concomitant antibiotics, antimicrobial allergies, and the reason why the culture was sent. Hospital staff members were unaware of the chart review.

The sample included all inpatients of the Ottawa Hospital (General and Civic campuses) and the University of Ottawa Heart Institute who had an indwelling catheter in place for a minimum of $72 \mathrm{~h}$ before a positive urine culture and an absence of UTI signs or symptoms. A positive urine culture was defined as the growth of at least $10^{8} \mathrm{CFU} / \mathrm{L}$ of bacteria or $10^{6} \mathrm{CFU} / \mathrm{L}$ of yeast, in which the microbiology laboratory at The Ottawa Hospital identified a specific microorganism(s). 'Asymptomatic' was defined as the absence of frequency, dysuria, urgency and suprapubic tenderness. In the case of paraplegic and quadriplegic patients, 'asymptomatic' was defined as no additional muscle spasticity above baseline. All patients 18 years of age or older were included in the present study. Urinary catheters had to remain in place for at least $48 \mathrm{~h}$ after the positive culture for patients to be included in the study.

Patients were excluded if they were admitted to hospital with an indwelling catheter and/or had been in hospital for less than three days, as were patients with a temperature of at least $38.3^{\circ} \mathrm{C}$ over two consecutive readings within a $12 \mathrm{~h}$ period and/or a white blood cell count above $10.5 \times 10^{9} / \mathrm{L}$ (on the day the culture was sent). The following patients were also excluded: pregnant women; patients undergoing intermittent catheterization; renal transplant patients; those located in the intensive care unit, cardiac care unit or cardiac surgery unit; patients with suspected or confirmed abnormalities of the urinary tract; patients with nephrolithiasis; and those who were scheduled to undergo genitourinary manipulation within $24 \mathrm{~h}$ of the culture. Immunocompromised patients were also excluded and were defined as patients with HIV disease (CD4 count of less than 500 cells $/ \mathrm{mL}$ ), patients dependant on dialysis, or any patient receiving immunosuppressive therapy including corticosteroids (greater than $10 \mathrm{mg} /$ day of prednisone or equivalent for greater than two consecutive weeks), chemotherapy, or antirejection agents (azathioprine, cyclosporine, tacrolimus, sirolimus and mycophenolate). Patients with bacteremia or suspected/confirmed infections of the upper urinary tract, such as prostatitis, pyelonephritis, and renal or perinephritic abscesses, were also excluded. The Ottawa Hospital and the University of Ottawa Heart Institute research ethics boards provided written approval of the study protocol.

\section{Statistical analysis}

Based on the criteria outlined above, the proportion of inappropriately managed patients was determined. Descriptive statistics were used to characterize this population, defining a CI of $95 \%$. A univariate analysis of the patients appropriately and inappropriately managed was completed using the SPSS statistical program (version 10.0.5, SPSS Inc, USA). Differences between the two groups were examined with the use of Fisher's exact test, Mann-Whitney $\mathrm{U}$ test and $\chi^{2}$ analysis, all of which reported two-sided $\mathrm{P}$ values.

\section{RESULTS}

From March 3 to March 28, 2003, 119 catheterized patients with a positive urine culture were screened; of these, 29 patients were included in the present study (Figure 1). Fifteen patients originated from the General campus and 14 from the Civic campus. All patients from the University of Ottawa Heart Institute were excluded after screening. There were 22 women (76\%) and seven men (24\%) included, and the mean age was 77.8 years (range 52 to 94 years of age).

Of the 29 patients, 15 (52\%) were prescribed antimicrobials and were therefore considered to be inappropriately managed. The two study groups were similar with respect to age, sex, service (medical versus surgical) and campus.

The results of the univariate analysis are summarized in Table 1. Patients in the appropriately managed group had a longer duration of hospital stay and catheterization to positive urine culture and were more likely to have a history of antimicrobial allergy.

Seven different organisms were isolated from urine cultures during the study (Figure 2). Six patients had more than one organism isolated (three patients each from the appropriately and inappropriately managed groups). Both groups had two patients with bacteria and yeast, and both groups had one patient with two bacteria together. A difference was observed between those appropriately managed versus those inappropriately managed among patients with candiduria compared with bacteriuria (Table 1).

Patients in the inappropriately managed group were started on antimicrobial therapy a median of two days (range one to seven days) after the culture was sent. Three different antibiotics 


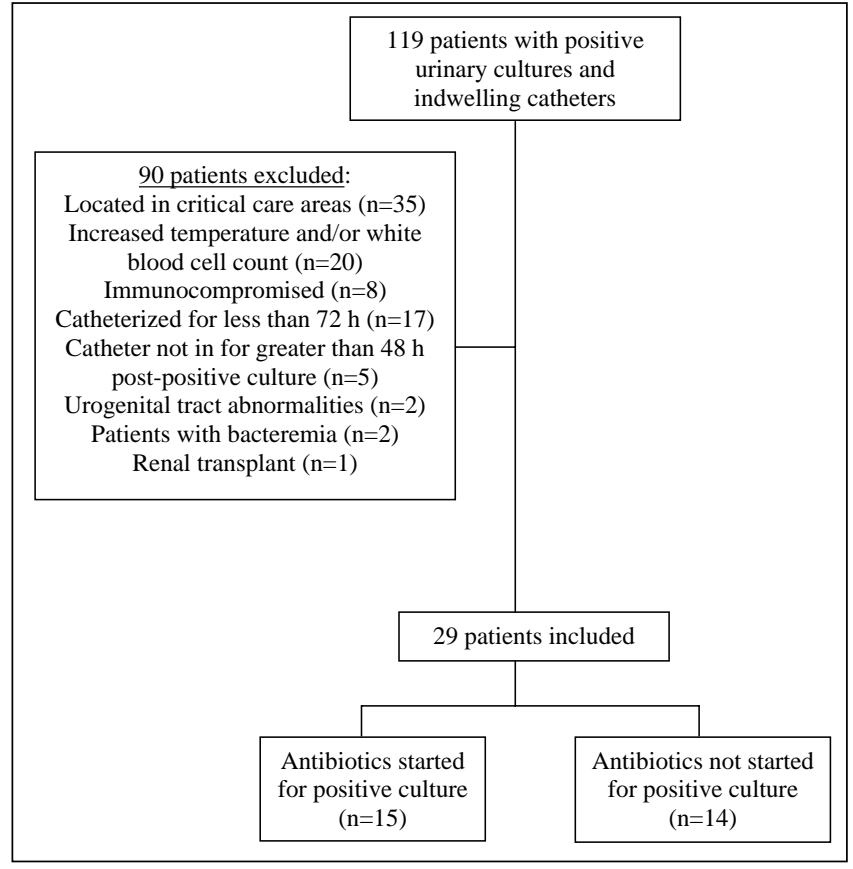

Figure 1) Flow chart of patients screened

were prescribed in these patients: ciprofloxacin $(33 \%)$; cotrimoxazole (47\%); and amoxicillin (20\%). No antifungals were used. Oral antibiotics were prescribed in all cases, and $80 \%$ of patients were treated for a duration of seven days. In 14 cases, the urinary catheter was either changed $(n=4)$ or removed $(n=10)$ after the identification of a positive urine culture during the five-day observation period.

On inclusion into the study, eight patients were on concomitant antimicrobial therapy for other indications (two patients [13\%] from the inappropriate management group and six patients [43\%] from the appropriate management group) (Table 1). The two patients in the inappropriate management group received antimicrobials for less than $24 \mathrm{~h}$ for surgical prophylaxis. The six patients in the appropriately managed group had Candida species cultured while on antibiotics for bacterial infections.

\section{DISCUSSION}

Through the present investigation, we determined the degree to which antimicrobials were being prescribed for asymptomatic CAUTI at The Ottawa Hospital and the University of Ottawa Heart Institute. Over one-half (52\%) of patients were being inappropriately managed with the initiation of antimicrobials for their positive urine culture.

The patient demographics and organisms cultured are similar to that reported in the literature in patients with CAUTIs $(1,5,7,9)$. Our observations suggest a trend toward the decreased use of antimicrobials in patients with a longer duration of catheterization and length of hospital stay, and the presence of an antibiotic allergy. None of the patients with yeast were treated with antifungal agents, whereas $68 \%$ of the patients (15 of 22) with bacteriuria received antibacterials.

The most significant risks associated with urinary catheterization are pyelonephritis, bacteremia and sepsis. The frequency of bacteremia varies considerably in the literature, from as low as $1 \%$ to as high as $5 \%(2,3,6,10,11)$. In a recent prospective
TABLE 1

Univariate analysis of appropriately and inappropriately managed patients

\begin{tabular}{|c|c|c|c|}
\hline \multirow[b]{2}{*}{ Variable } & \multicolumn{2}{|c|}{$\begin{array}{l}\text { Antimicrobial started } \\
\text { for a positive culture? }\end{array}$} & \multirow[b]{2}{*}{$\mathbf{P}$} \\
\hline & Yes* $^{*}(n=15)$ & No $(n=14)$ & \\
\hline \multicolumn{4}{|l|}{ Organism $^{\dagger}, \mathrm{n}(\%)$} \\
\hline Yeast & $0(0)$ & $7(50)$ & $0.002^{\ddagger}$ \\
\hline Bacteria & $13(87)$ & $5(36)$ & $0.005^{\S}$ \\
\hline Both & $2(13)$ & $2(14)$ & $1.0^{\ddagger}$ \\
\hline \multicolumn{4}{|l|}{$\begin{array}{l}\text { Duration of stay to } \\
\text { positive culture (days) }\end{array}$} \\
\hline Median (range) & $8(4-51)$ & $23.5(3-95)$ & $0.012^{\pi}$ \\
\hline \multicolumn{4}{|l|}{$\begin{array}{l}\text { Duration of catheterization } \\
\text { to positive culture (days) }\end{array}$} \\
\hline Median (range) & $6(3-29)$ & $17.5(3-95)$ & $0.08 \pi$ \\
\hline \multicolumn{4}{|l|}{$\begin{array}{l}\text { Action taken with the } \\
\text { indwelling catheter, } \mathrm{n}(\%)\end{array}$} \\
\hline Removed $^{\star *}$ & $6(40)$ & $4(29)$ & $0.805^{\S}$ \\
\hline Changed & $2(13)$ & $2(14)$ & $0.941^{\ddagger}$ \\
\hline Neither & $7(47)$ & $8(57)$ & $0.573 \S$ \\
\hline $\begin{array}{l}\text { Patient already on concomitant } \\
\text { antibiotics, } \mathrm{n}(\%)\end{array}$ & $2(13)$ & $6(42)$ & $0.109 \ddagger$ \\
\hline \multicolumn{4}{|l|}{ Allergy status to antimicrobials } \\
\hline Patients with an allergy, $\mathrm{n}(\%)$ & $3(20)$ & $8(57)$ & $0.06^{\ddagger}$ \\
\hline \multicolumn{4}{|l|}{$\begin{array}{l}\text { Culture sent by physician } \\
\text { or nurse }\end{array}$} \\
\hline Ordered by physician, $\mathrm{n}(\%)$ & $10(67)$ & $7(50)$ & $0.362^{\S}$ \\
\hline
\end{tabular}

*Patients started on antimicrobials were defined as inappropriate management'; 'Six patients had two organisms identified in their positive culture ${ }^{\ddagger}$ Fisher's exact test; $\S \chi^{2}$ test; "Mann-Whitney $U$ test; ${ }^{* \star}$ Catheter removed after 48 h postpositive culture

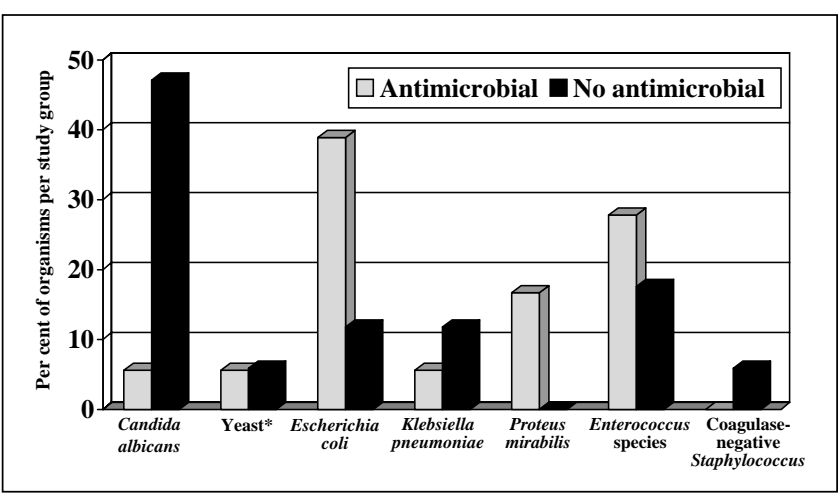

Figure 2) Organisms identified in the positive urine cultures, differentiated by whether antimicrobial therapy was started. *Other than Candida albicans

study of hospitalized, catheterized patients, 224 of 1497 patients $(15 \%)$ developed a CAUTI after an average catheterization duration of 6.4 days (10). Of these patients, four (1.8\%) went on to develop a bloodstream infection in which the same organism was isolated from both blood and urine cultures. In only one of the four bacteremias, however, did the bacteria unequivocally originate from the urinary tract (10).

It is well established in the literature that asymptomatic CAUTIs should not be treated with antimicrobial therapy $(1,3-9)$. Likewise, prophylactic antimicrobials may postpone bacteriuria, but they do not prevent further complications and 
can lead to a reservoir of antibiotic-resistant organisms within the hospital $(1-3,6,10,12)$.

A study conducted by Warren et al (13) found no difference between groups treated with cephalexin monohydrate versus placebo for cases of susceptible bacteriuria with respect to febrile episodes, catheter obstruction, renal function or the use of nonprotocol antibiotics. Furthermore, that study isolated a greater number of resistant strains from the treatment group compared with the control group (47\% versus 26\%, respectively) (13). Garibaldi et al (14) examined the feasibility of bacterial surveillance of catheterized patients to selectively treat those colonized, with the goal of preventing symptomatic infection. From their work, it was estimated that 250 urine cultures would need to be performed in catheterized patients to prevent one symptomatic UTI with prophylactic antibiotics, assuming that antibiotics were $100 \%$ effective $(6,14)$.

The practice of using prophylactic antibiotics in catheterized patients has been evaluated in prospective randomized, controlled trials $(15,16)$. A short-lived decrease in bacteriuria has been observed, along with a subsequent increase in the incidence of resistant organisms. These studies emphasize the risk of developing resistant organisms secondary to inappropriate antimicrobial therapy. A more recent study (17) compared ciprofloxacin with placebo for the prevention of bacteriuria and symptomatic UTIs in postoperative surgical patients catheterized from three to 14 days. This study found significantly less bacteriuria and symptomatic UTIs in the ciprofloxacin group compared with placebo (17). Although no ciprofloxacin-resistant, Gram-negative organisms emerged in the ciprofloxacin-treated patients during the study period, the organisms cultured from the ciprofloxacin patients were primarily Gram-positive, the majority of which were resistant to ciprofloxacin (17).

Similarly, the treatment of candiduria in asymptomatic catheterized patients is not recommended. A randomized, double-blind, placebo-controlled trial by Sobel et al (18) examined the efficacy of $200 \mathrm{mg}$ of fluconazole daily for 14 days versus placebo for the treatment of asymptomatic candiduria. In the subset of catheterized patients completing all 14 days of treatment $(n=129)$, candiduria was cleared in $52 \%$ of cases in the treatment group compared with $25 \%$ in the placebo group $(\mathrm{P}=0.002)$. However, two weeks post-therapy, the incidence of candiduria was similar between the treatment and placebo groups (61\% versus 56\%, respectively; $\mathrm{P}=0.7$ ) (18).

Bacteriuria and candiduria are difficult to eradicate as long as the catheter remains in place due to the presence of biofilms, which enhance an organism's ability to colonize a urinary catheter and protect them from antimicrobials and host defense mechanisms (1,3). A study by Bergqvist et al (19) found that one-quarter of all urine samples taken through an indwelling catheter had organisms that were not cultured from the bladder. Thus, changing or removing the catheter in patients with bacteriuria is recommended $(1,3,7)$. Because only one-half of the patients in the present study had their catheter removed or changed, this practice requires reinforcement with health professionals in the management of CAUTIs.

All of the patients in the inappropriate management group in the present study who had their catheter changed or removed received a full course (five to seven days) of antibiotics. As a result, it was assumed that antibiotics were not used simply to prevent bacteremia during catheter manipulation, as a single dose of antibiotic would suffice for this indication.
In addition, two of six patients in the inappropriate management group whose catheters were removed were prescribed antibiotics one or two days after catheter removal. These two cases could be considered appropriate if the intent was to clear the bacteriuria after catheter removal. It can be argued, however, that it may be more desirable to determine whether the bacteriuria is persistent or whether the patient develops symptoms following catheter removal before initiating antimicrobial therapy.

There are a number of limitations in the present study that must be considered. Given the small sample size, a larger study would be needed to confirm the differences that were found between the two patient groups and to identify potentially adverse consequences of unnecessary antibiotic use in this patient population.

The restrictive exclusion criteria used in the present study may have eliminated patients for whom the recommendation of not treating asymptomatic CAUTIs would also apply. Specifically, the exclusion of patients in critical care areas, patients with a white blood cell count above $10.5 \times 10^{9} / \mathrm{L}$ (the upper limit of normal at The Ottawa Hospital) and patients on at least $10 \mathrm{mg}$ of prednisone could be challenged. The decision to treat CAUTIs in this population is often more complicated, and these patients were therefore excluded to obtain a noncontroversial study population. There are also obvious limitations to strictly relying on chart information to assess the presence or absence of patient symptoms.

Although our number of inappropriately managed patients is conservative ( 15 patients in four weeks), this translates to almost 200 patients/year receiving unnecessary antibiotic therapy.

Our review demonstrates that, contrary to recommendations from the literature, $68 \%$ of patients were prescribed antibiotics to manage asymptomatic catheter-associated bacteriuria at The Ottawa Hospital and therefore received antibiotics for which there was no indication. Catheter-associated candiduria, however, appears to be appropriately managed. Educational efforts directed toward physicians and other health care professionals (ie, nurses and pharmacists) are warranted, as is follow-up to ensure a change of practice. Curtailing such unnecessary antibiotic use will decrease costs, decrease the risk of adverse effects to patients and potentially decrease antimicrobial resistance.

ACKNOWLEDGEMENTS: The authors are indebted to Salmaan Kanji PharmD (Clinical Pharmacy Specialist - Critical Care, Department of Pharmacy at The Ottawa Hospital) for statistical analysis, and to Kirsten Woodend RN MSc PhD (Director of Research for the Canadian Pharmacists Association) for statistical advice.

The authors would like to disclose that there were no conflicts of interest throughout the duration of the study. The study was conducted in whole at The Ottawa Hospital and no funding was received.

\section{REFERENCES}

1. Sedor J, Mulholland SG. Hospital-acquired urinary tract infections associated with the indwelling catheter. Urol Clin North Am 1999;26:821-8.

2. Saint S, Lipsky BA. Preventing catheter-related bacteriuria: Should we? Can we? How? Arch Intern Med 1999;159:800-8.

3. Saint $\mathrm{S}$, Chenoweth CE. Biofilms and catheter-associated urinary tract infections. Infect Dis Clin North Am 2003;17:411-432. 
4. Lundstrom T, Sobel J. Nosocomial candiduria: A review. Clin Infect Dis 2001;32:1602-7.

5. Nicolle LE. Asymptomatic bacteriuria: When to screen and when to treat. Infect Dis Clin North Am 2003;17:367-94.

6. Warren JW. Catheter-associated urinary tract infections. Infect Dis Clin North Am 1997;11:609-22.

7. Whitworth JA. Management of asymptomatic bacteriuria. Aust N Z J Med 1981;11:321-8.

8. Nicolle LE. A practical guide to the management of complicated urinary tract infection. Drugs 1997;53:583-92.

9. Warren JW. Nosocomial urinary tract infections. In: Mandell GL, Bennett JE, Dolin R, eds. Principles and Practice of Infectious Diseases, 5th edn. Philadelphia: Churchill Livingstone, 2000:3028-39.

10. Tambyah PA, Maki DG. Catheter-associated urinary tract infection is rarely symptomatic: A prospective study of 1,497 catheterized patients. Arch Intern Med 2000;160:678-82.

11. Bregenzer T, Frei R, Widmer AF, et al. Low risk of bacteremia during catheter replacement in patients with long-term urinary catheters. Arch Intern Med 1997;157:521-5.

12. Hustinx WN, Mintjes-de Groot AJ, Verkooyen RP, Verbrugh HA. Impact of concurrent antimicrobial therapy on catheter-associated urinary tract infection. J Hosp Infect 1991;18:45-56.
13. Warren JW, Anthony WC, Hoopes JM, Muncie HL Jr. Cephalexin for susceptible bacteriuria in afebrile, long-term catheterized patients. JAMA 1982;248:454-8.

14. Garibaldi RA, Mooney BR, Epstein BJ, Britt MR. An evaluation of daily bacteriologic monitoring to identify preventable episodes of catheter-associated urinary tract infection. Infect Control 1982;3:466-70.

15. Mountokalakis T, Skounakis M, Tselentis J. Short-term versus prolonged systemic antibiotic prophylaxis in patients treated with indwelling catheters. J Urol 1985;134:506-8.

16. Nyren P, Runeberg L, Kostiala AI, Renkonen OV, Roine R. Prophylactic methenamine hippurate or nitrofurantoin in patients with an indwelling urinary catheter. Ann Clin Res 1981;13:16-21.

17. van der Wall E, Verkooyen RP, Mintjes-de Groot J, et al. Prophylactic ciprofloxacin for catheter-associated urinary-tract infection. Lancet 1992;339:946-51.

18. Sobel JD, Kauffman CA, McKinsey D, et al. Candiduria: A randomized, double-blind study of treatment with fluconazole and placebo. The National Institute of Allergy and Infectious Diseases (NIAID) Mycoses Study Group. Clin Infect Dis 2000;30:19-24.

19. Bergqvist D, Bronnestam R, Hedelin H, Stahl A. The relevance of urinary sampling methods in patients with indwelling Foley catheters. Br J Urol 1980;52:92-5. 


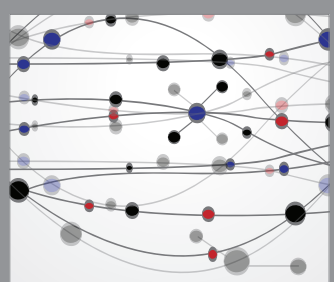

The Scientific World Journal
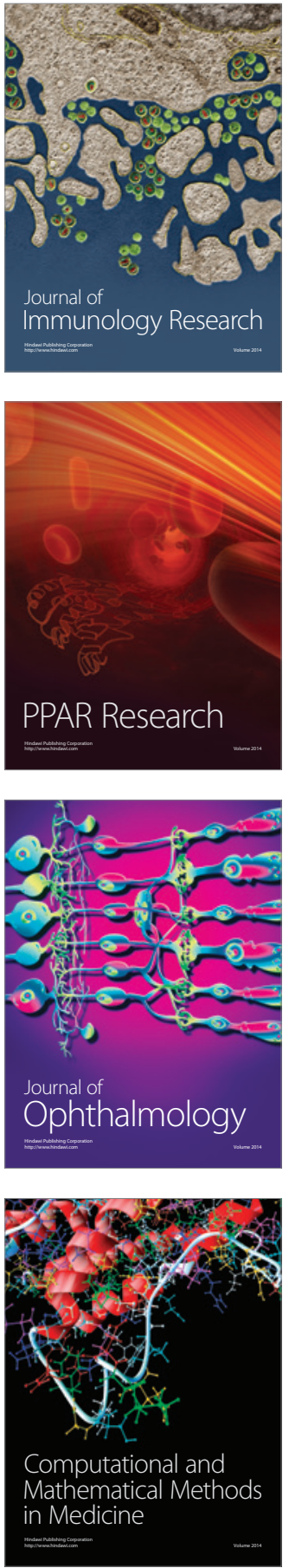

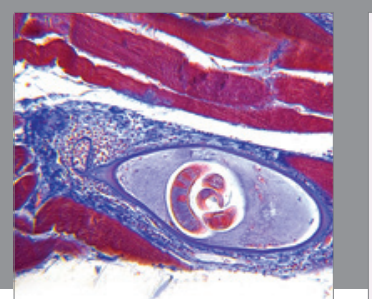

Gastroenterology Research and Practice

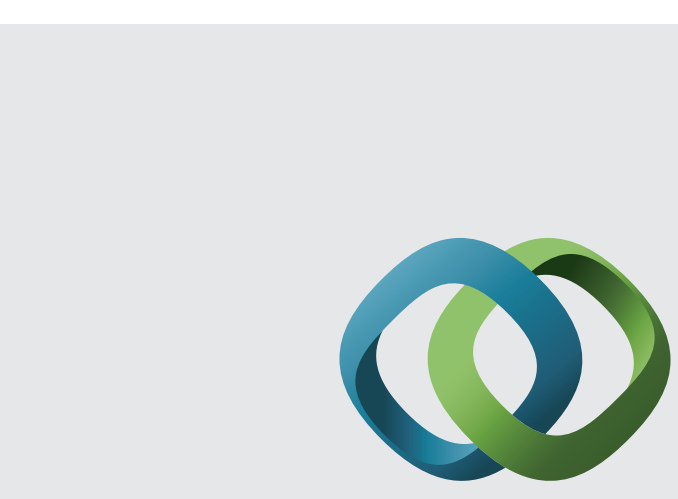

\section{Hindawi}

Submit your manuscripts at

http://www.hindawi.com
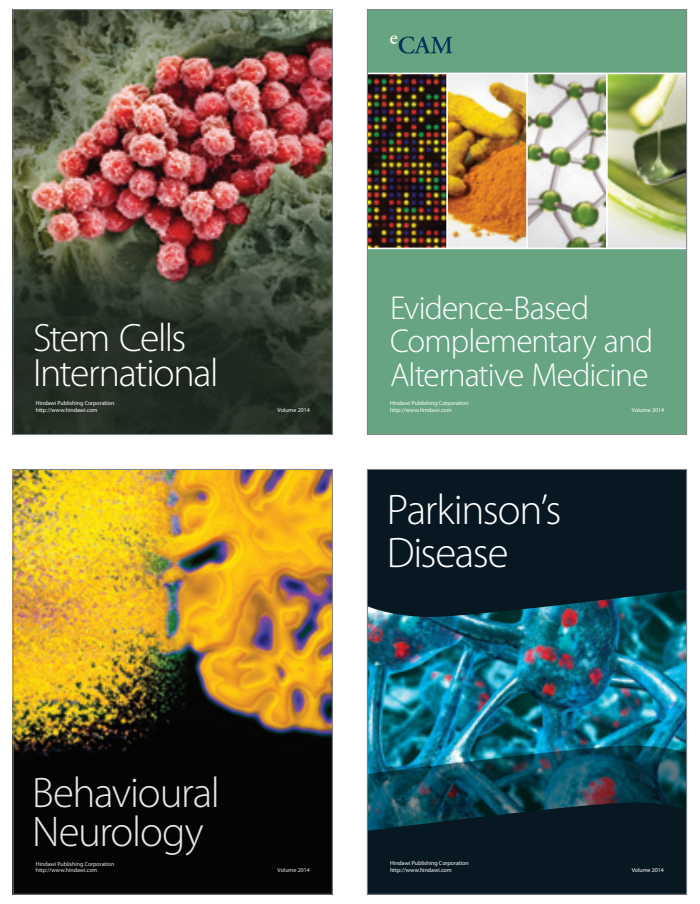
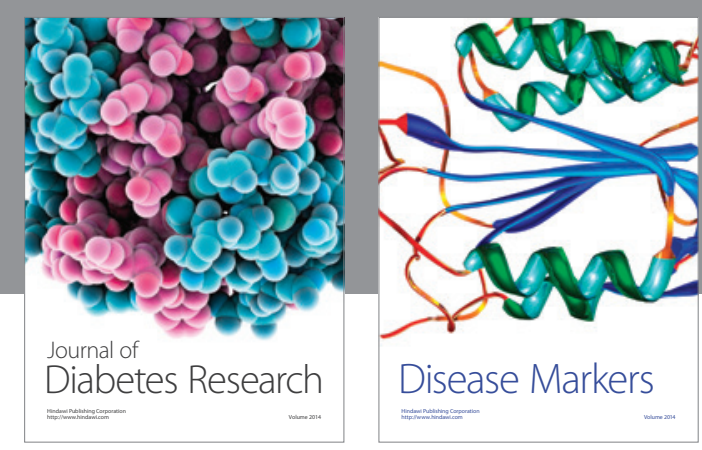

Disease Markers
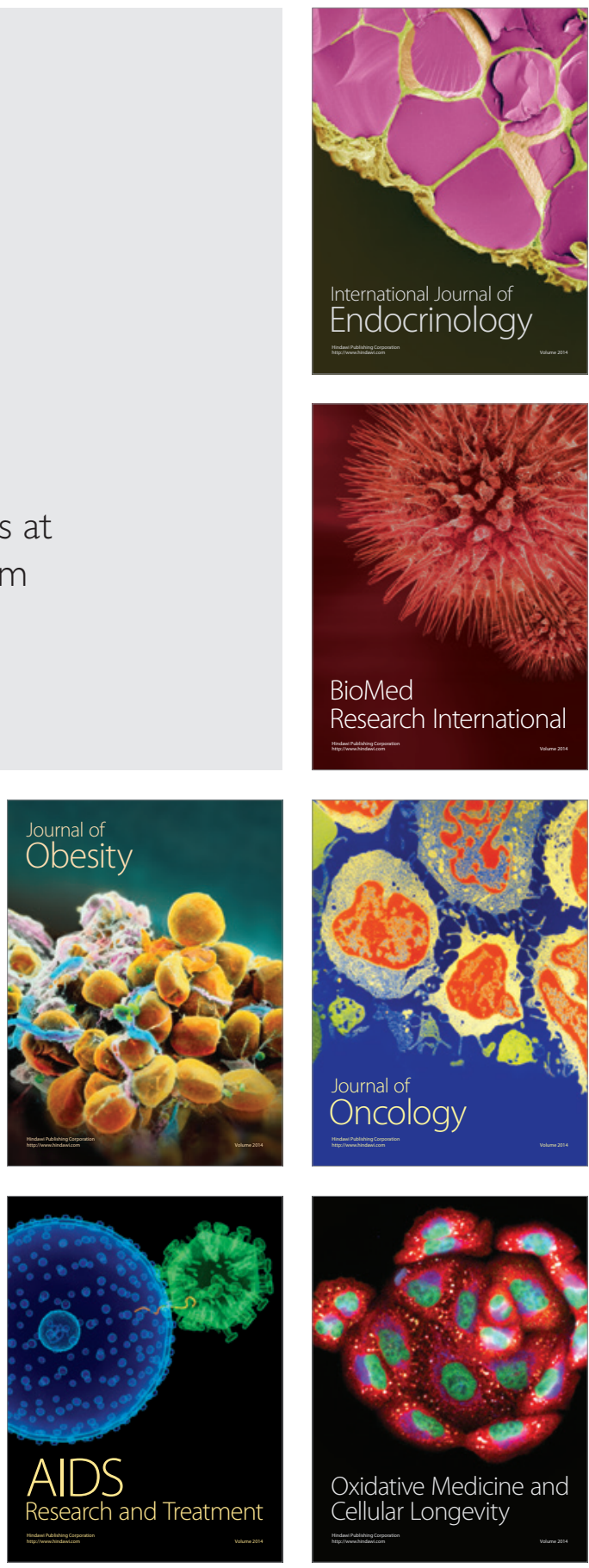